\title{
Integrating body and organ size in Drosophila: recent advances and outstanding problems
}

\author{
Christen Kerry Mirth ${ }^{1}$ and Alexander W. Shingleton ${ }^{2}$ * \\ ${ }_{1}^{1}$ Development, Evolution and the Environment Lab, Instituto Gulbenkian de Ciência, Fundação Calouste Gulbenkian, Oerias, Portugal \\ 2 Department of Zoology, Michigan State University, East Lansing, MI, USA
}

\author{
Edited by: \\ Michael O'Connor, University of \\ Minnesota, USA \\ Reviewed by: \\ Kirst King-Jones, University of \\ Alberta, Canada \\ Ryusuke Niwa, University of Tsukuba, \\ Japan \\ Arash Bashirullah, University of \\ Wisconsin - Madison, USA \\ *Correspondence: \\ Christen Kerry Mirth, Development, \\ Evolution and the Environment Lab, \\ Instituto Gulbenkian de Ciência, \\ Fundação Calouste Gulbenkian, Rua \\ da Quinta Grande, 6, 2780-156 \\ Oeiras, Portugal. \\ e-mail: christen@igc.gulbenkian.pt; \\ Alexander W. Shingleton, Department \\ of Zoology, Michigan State University, \\ East Lansing, 203 Natural Science \\ Building, East Lansing, MI 48824, \\ USA. \\ e-mail: shingle9@msu.edu
}

Over the past two decades, fundamental strides in physiology and genetics have allowed us to finally grasp the developmental mechanisms regulating body size, primarily in one model organism: the fruit fly Drosophila melanogaster. In Drosophila, as in all animals, final body size is regulated by the rate and duration of growth. These studies have identified important roles for the insulin and the target of rapamycin (TOR) signaling pathways in regulating the growth rate of the larva, the stage most important in determining final adult size. Furthermore, they have shown that the insulin/TOR pathway interacts with hormonal systems, like ecdysone and juvenile hormone, to regulate the timing of development and hence the duration of growth. This interaction allows the growing larvae to integrate cues from the environment with environmentally sensitive developmental windows to ensure that optimal size and proportions are reached given the larval rearing conditions. Results from this work have opened up new avenues of studies, including how environmental cues are integrated to regulate developmental time and how organs maintain proportional growth. Other researchers interested in the evolution of body size are beginning to apply these results to studies of body size evolution and the generation of allometry. With these new findings, and with the developments to come, the field of size control finds itself in the fortunate position of finally being able to tackle century old questions of how organisms achieve final adult size and proportions. This review discusses the state of the art of size control from a Drosophila perspective, and outlines an approach to resolving outstanding issues.

Keywords: environmental effects on body size, insulin/target of rapamycin signaling, ecdysone, juvenile hormone regulation of organ growth, growth rates, developmental timing, genetics of body size and proportions

\section{INTRODUCTION}

Body size and relative proportions of organs are characteristic features that distinguish one species from the next. The alteration of size and shape to produce the wide variety of forms seen in nature has fascinated biologists for centuries. Over the past 10 years, researchers have used the fruit fly Drosophila melanogaster to approach the problem of how development ensures that organisms achieve the appropriate body and organ size. These efforts have provided insight into four broad and partially overlapping sub-disciplines of body size regulation (Figure 1). They have: (1) elucidated how environmental signals regulate developmental programs to control size; (2) highlighted how environmentally regulated hormone production controls the progression of development and duration of growth; (3) addressed the genetic underpinnings of population-level variation in body size; and (4) suggested mechanisms that allow the body to coordinate the growth of organs to maintain correct proportions. Strikingly, the overall picture from these studies demonstrates that often the same signaling pathways are employed to mediate each of these different aspects of size regulation. Our new challenge is to synthesize these different data into a cohesive, and coherent, understanding of body size regulation. Here we begin to address this challenge by concentrating on recent findings, mostly in Drosophila, with the intentions of integrating the relevant data across these sub-disciplines in size control and highlighting outstanding problems.

\section{DROSOPHILA AS A MODEL FOR UNDERSTANDING BODY SIZE REGULATION}

In Drosophila, as in all insects, adult body size is defined by growth mostly in the larval but also in pupal stages. During metamorphosis, the rigid exoskeleton of the adult body differentiates and constrains any future increase in the body's dimensions. For this reason, understanding the mechanisms regulating the final size and proportions of the adult requires examining growth in the larval stages.

Drosophila goes through three larval stages before initiating metamorphosis. During this period, both the larval tissues and the tissues that will metamorphose to form the adult body, called the imaginal tissues, increase in mass, and undergo development in response to internal physiological signals and to external cues from the environment. The culmination of environmental, physiological, genetic, and organ-specific effects on growth acts at this time to determine the final size and proportions of the adult body (Figure 1). 
A Environmental Regulation of Body Size

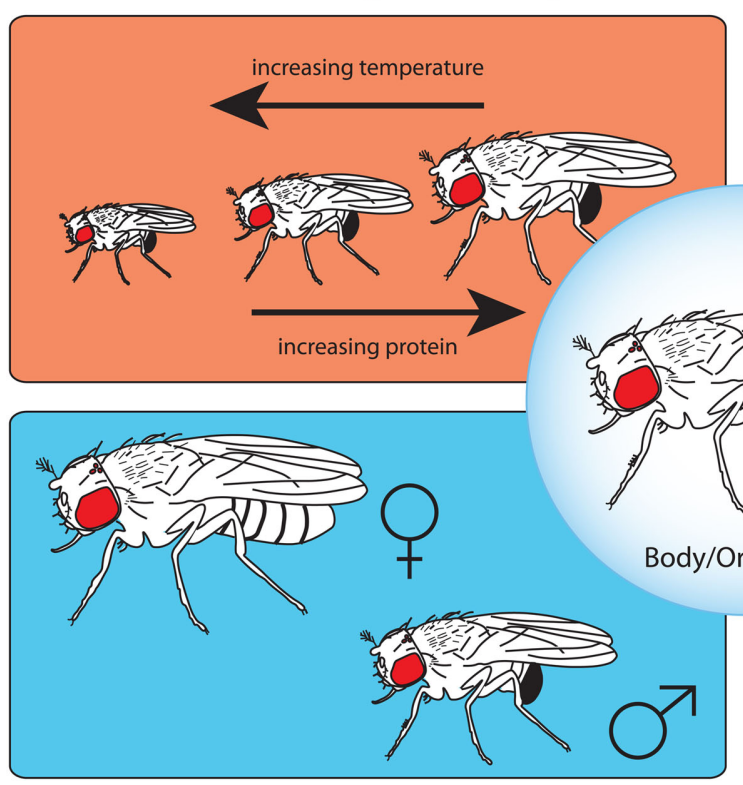

C Genetic Regulation of Body Size
B Physiological Regulation of Body Size
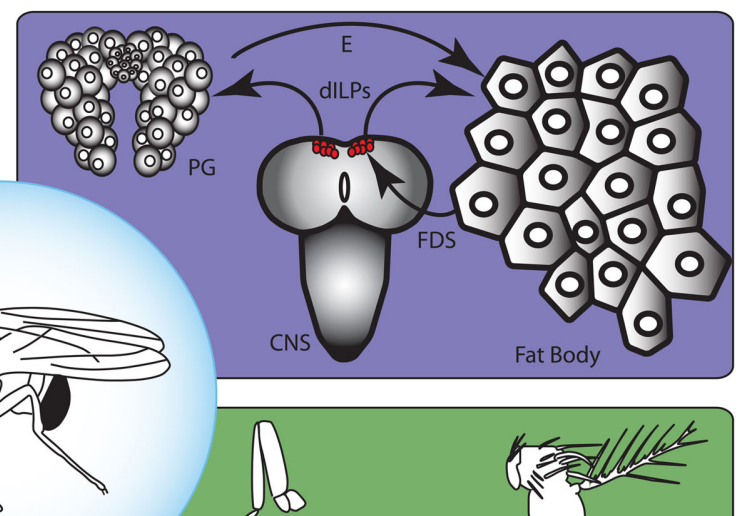

No

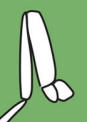

gan Size

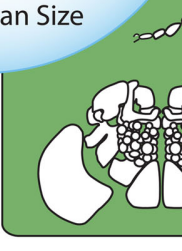

D
FIGURE 1 | To produce a correctly proportioned animal whose physiology and size is appropriate for the environmental conditions in which it was reared, body size needs to be regulated on several levels. First, the

environment controls developmental processes that determine final body size (A). As temperature increases, body size tends to decrease. Furthermore, as protein content in the larval food increases, adult size increases. This is due to the action of environmentally regulated signaling cascades on mechanisms that regulate growth rate and developmental timing (B). The fat body senses nutritional conditions and communicates this to the central nervous system (CNS) via a fat body derived signal (FDS). This FDS acts on the insulin

\section{ENVIRONMENTAL REGULATION OF BODY SIZE: SIGNALING PATHWAYS CONTROLLING GROWTH IN RESPONSE TO ENVIRONMENTAL CUES}

A host of environmental cues, including temperature (Partridge et al., 1994; Santos et al., 1994; Nunney and Cheung, 1997; French et al., 1998; Robinson and Partridge, 2001), oxygen levels (Peck and Maddrell, 2005), infection (DiAngelo et al., 2009), and nutrition (Beadle et al., 1938; Robertson, 1963) modify developmental programs to produce organisms of an appropriate size. Recent work has focused, for the most part, on defining the signaling pathways that allow nutrition to modulate size.

For most organisms, the insulin/target of rapamycin (TOR) signaling pathways act to coordinate the rate of growth with nutritional signals. Drosophila produces seven insulin-like peptides (dILPs) in the central nervous system (CNS), gut, imaginal disks, and fat body (Brogiolo et al., 2001). Most of the nutritiondependent regulation of growth is thought to arise from dILP secretion by the brain. Here, seven pairs of neurosecretory cells in the protocerebrum produce dILP2, 3, and 5 (Ikeya et al., 2002). Ablating these neurosecretory cells greatly reduces larval, hence adult, body size (Ikeya et al., 2002; Rulifson et al., 2002). Although dILP2 transcription does not depend on nutrition, starvation reduces the synthesis of both dILP3 and 5 mRNA (Ikeya et al., producing neurosecretory cells to regulate the production of Drosophila insulin-like peptides (dILPs). dILPs, in turn regulate growth rate and the production of the steroid molting hormone ecdysone (E) by the prothoracic gland cells thereby determining the duration of the growth period. For any given environmental condition, the genetic background contributes to overall body size (C). For example, independent of rearing conditions, males are typically smaller than females. Lastly, in addition to this physiological regulation of whole body size, the size of individual organs is controlled by mechanisms that regulate organ-autonomous growth and those that ensure organs grow in proportion to one another (D).
2002). Furthermore, starvation prevents the secretion of both dILP2 and dILP5 by these cells (Géminard et al., 2009).

Once released into the hemolymph, dILPs activate a single insulin receptor ( $\mathrm{InR})$ in target tissues (Brogiolo et al., 2001). Activation of InR initiates a phosphokinase signal transduction cascade, the insulin signaling pathway, that regulates growth rates both by activating positive growth regulators, such as Akt and RAS/MAP Kinase (Yenush et al., 1996), but also by suppressing negative growth regulators, such as FOXO and TSC1/2 (Gao and Pan, 2001; Potter et al., 2001; Gao et al., 2002; Garami et al., 2003; Kramer et al., 2003). TSC1/2 negatively regulates growth by suppressing the activity of a second nutrient-sensing signal transduction cascade, the TOR signaling pathway, which is believed to be one of the most ancient nutrient-sensing pathways, and is present in organisms as diverse as bacteria, plants, and animals (Wullschleger et al., 2006). The TOR pathway responds directly to intracellular amino acid concentration (Gao et al., 2002), either via the TOR complex itself (Kim et al., 2002) or its upstream activator Ras homolog enriched in the brain (Rheb; Garami et al., 2003; Saucedo et al., 2003; Bai et al., 2007). Activation of TOR in turn results in the activation of Akt (Sarbassov et al., 2005), thus the insulin and TOR pathways converge to activate at least some of the same downstream targets. 
In Drosophila larvae, the insulin/TOR pathway interacts in a humoral fashion to regulate the growth of the larva in response to nutrition. The locus of this interaction is the fat body, an organ that serves as the primary storage tissue and nutrient relay center. During feeding, the influx of amino acids into the fat body, through the activity of amino acid transporters, stimulates TOR signaling (Colombani et al., 2003), which causes the release of a nutrition-dependent fat body derived signal (FDS) whose nature is, as of yet, unknown. The FDS in turn regulates growth of the surrounding tissue (Britton and Edgar, 1998; Colombani et al., 2003), in part by regulating the release of dILPs from the brain (Géminard et al., 2009). Thus, the fat body couples the level of dietary amino acids to dILP production (Géminard et al., 2009): a reduction in developmental nutrition suppresses TOR signaling in the fat body which in turn reduces insulin signaling in other tissues by blocking the release of dILPs.

While adult size results from growth during the larval feeding stage, during the wandering larval stage and the non-motile pupal stage many of the developing adult organs grow and differentiate after the cessation of feeding even though the animal does not increase in mass. Growth during these periods presumably utilizes stored nutrients accumulated whilst larvae feed. Recent studies show that growth during these stages results from the production of dILP6 by the fat body, whose expression greatly increases at the onset of wandering behavior and during starvation (Okamoto et al., 2009; Slaidina et al., 2009; Chell and Brand, 2010). In both cases, continued growth and development must rely on stored nutrients, and the production of dILP6 by the fat body may serve as a signal that ensures growth is proportional to the amount of nutrient reserves. Thus the fat body mediates growth both during the feeding and non-feeding stages.
Insulin/TOR signaling responds to other environmental conditions. Drosophila infected with the symbiotic bacteria Wolbachia have higher levels of insulin/TOR signaling and show more moderate reductions in body size when insulin signaling is reduced throughout the whole body than uninfected individuals (Ikeya et al., 2009). Furthermore, the gut endosymbiont Lactobacillus plantarum increases growth and attenuates developmental delays in response to poor nutrition in larvae (Storelli et al., 2011). In the case of infection, the Toll signaling pathway is activated in the fat body, resulting in a decrease in insulin signaling in these cells and throughout the body (DiAngelo et al., 2009). Thus, insulin/TOR signaling may also regulate changes in body size and development time in response to the presence of infectious or commensal bacteria. For other environmental factors, such as temperature and oxidative stress, it is unclear whether insulin/TOR signaling plays a role.

At least in some cases, environmental signals appear to use divergent mechanisms to achieve similar overall results. Larvae reared at higher temperatures or lower nutrient conditions both produce smaller adults. Adults from larvae grown at higher temperatures have smaller wings (Partridge et al., 1994), much like adults from starved larvae (Figure 2). However, organs show different scaling relationships, or allometries, in response to temperature and nutrition (Shingleton et al., 2009). Changes in wing size generated by nutritional deprivation scale more-or-less proportionately with body size (isometric scaling), whereas changes in wing size resulting from rearing temperatures scale disproportionately (hyperallometric scaling; Shingleton et al., 2009). The result is that flies reared at lower temperatures have proportionally larger wings for their body size than flies reared at higher temperatures. Whether these scaling relationships represent differences in the signaling pathways used to regulate growth in response to nutrition

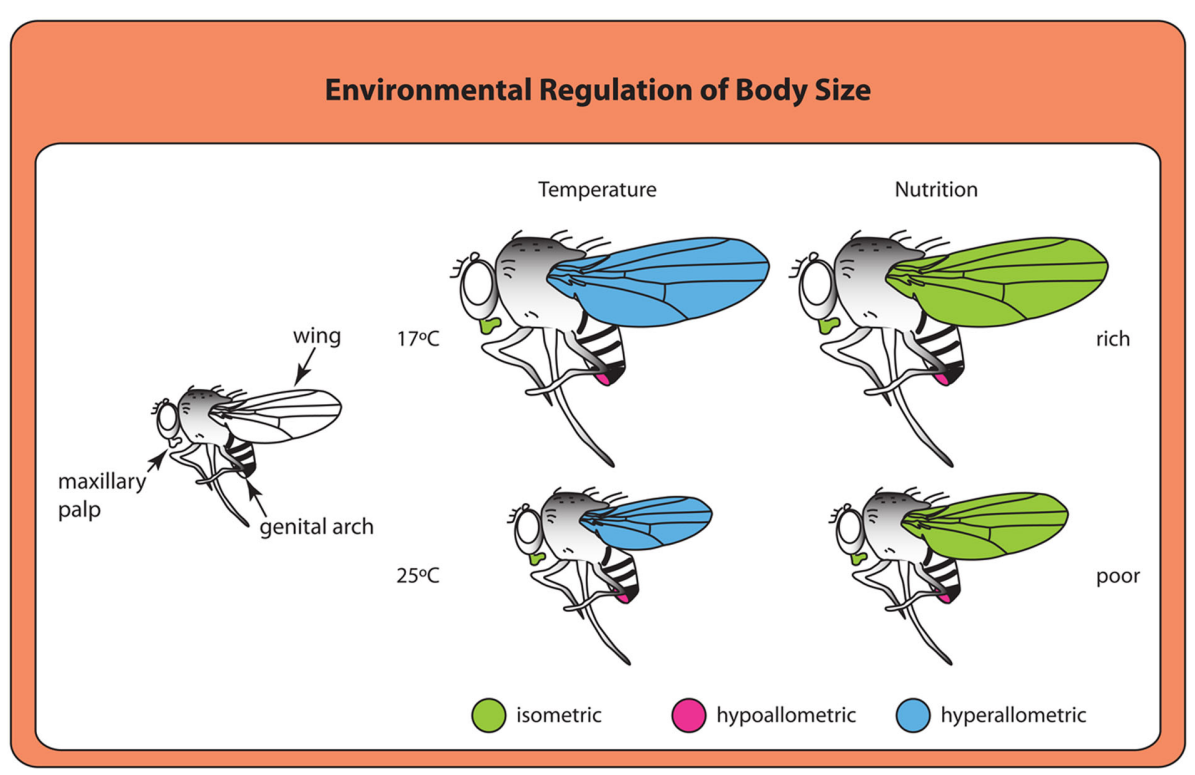

FIGURE 2 | Organs differ in their scaling relationships to overall body size depending on the type of environmental cue (Shingleton et al., 2009). Isometric scaling indicates that a structure scales proportionally with body size. Hyperallometric scaling occurs when the size of a structure increases disproportionately with increasing body size. Structures that are hypoallometric do not increase or increase very little with increasing body size. 
and temperature or differences in how cells respond to common growth regulatory pathways under different environmental conditions remains unclear and would be a fruitful area of future study.

\section{PHYSIOLOGICAL REGULATION OF BODY SIZE:} INTERACTIONS BETWEEN ENVIRONMENTALLY REGULATED SIGNALING PATHWAYS AND THE HORMONE SYSTEMS THAT CONTROL DEVELOPMENTAL TIMING

Attaining correct body size in a variable environment involves regulating the rate of growth, and also the length of the growth period. In Drosophila and many other organisms, the insulin/TOR pathway regulates growth rate at least in response to nutrition. Furthermore, this signaling pathway acts to control developmental time by regulating environmentally sensitive developmental transitions. These transitions, in turn, occur in response to the production of the steroid molting hormone, ecdysone, and the sesquiterpenoid "status quo" hormone, juvenile hormone (JH).

Developing insects show a number of developmental transitions that respond to environmental cues. Several environmentally dependent transitions control the onset of metamorphosis. Threshold size for metamorphosis is the minimal size at which a larva will molt to the last larval stage in preparation for metamorphosis rather than to another larval stage (Figure 3; Nijhout, 1975), minimal viable weight for pupariation and eclosion represents the minimal size to survive to metamorphosis and adulthood respectively (Figure 3; Nijhout and Williams, 1974a) and critical weight is the size above which starvation no longer delays metamorphosis (Figure 3; Nijhout and Williams, 1974a). Although these transitions are defined as a function of larval body size, in fact they most likely reflect environmentally sensitive regulation of hormone synthesis that correlates with body size. Once hormones surpass a stage-specific threshold, they cue the developmental transition and development progresses to the next stage.
Of these developmental transitions, critical weight and its regulation by developmental nutrition is best understood at the physiological and genetic level. In both the lepidopteran Manduca sexta and Drosophila, larvae starved in the early stages of the final larval instar, before reaching critical weight, either significantly delay the onset of metamorphosis (Beadle et al., 1938; Mirth et al., 2005; Shingleton et al., 2005; Stieper et al., 2008) and delay patterning of their presumptive adult tissues, the imaginal disks (Mirth et al., 2009), or die before achieving metamorphosis at all. In contrast, starving larvae post-critical weight does not delay metamorphosis (and actually accelerates it in Drosophila) and permits continued patterning of the wing imaginal disks (Mirth et al., 2005, 2009; Shingleton et al., 2005; Stieper et al., 2008).

The hormonal changes associated with attainment of critical size were first described for a lepidopteran, the tobacco hornworm Manduca sexta. Here, critical size triggers a decline in the level of circulating $\mathrm{JH}$, which, when it falls below a certain level, triggers cells in the brain to produce prothoracicotropic hormone (PTTH; Nijhout and Williams, 1974b). PTTH in turn stimulates the prothoracic gland to produce ecdysone (Dominick and Truman, 1985; Gilbert et al., 2002). It is the ecdysone pulse late in larval development that stimulates continued growth and patterning in the imaginal disks (Nijhout and Grunert, 2010), the cessation of feeding (and hence the end of body growth; Dominick and Truman, 1985), and ultimately pupation and metamorphosis (and hence the end of organ growth; Truman and Riddiford, 1974; Riddiford, 1993). Removal of the glands that synthesize JH, the corpora allata, causes premature onset of metamorphosis resulting in tiny adults (Nijhout and Williams, 1974b), identifying JH as the principle regulator of critical weight in Manduca.

The hormonal changes associated with attainment of critical weight are thought to be similar but not identical in Drosophila. One notable difference is that $\mathrm{JH}$ does not appear to control the

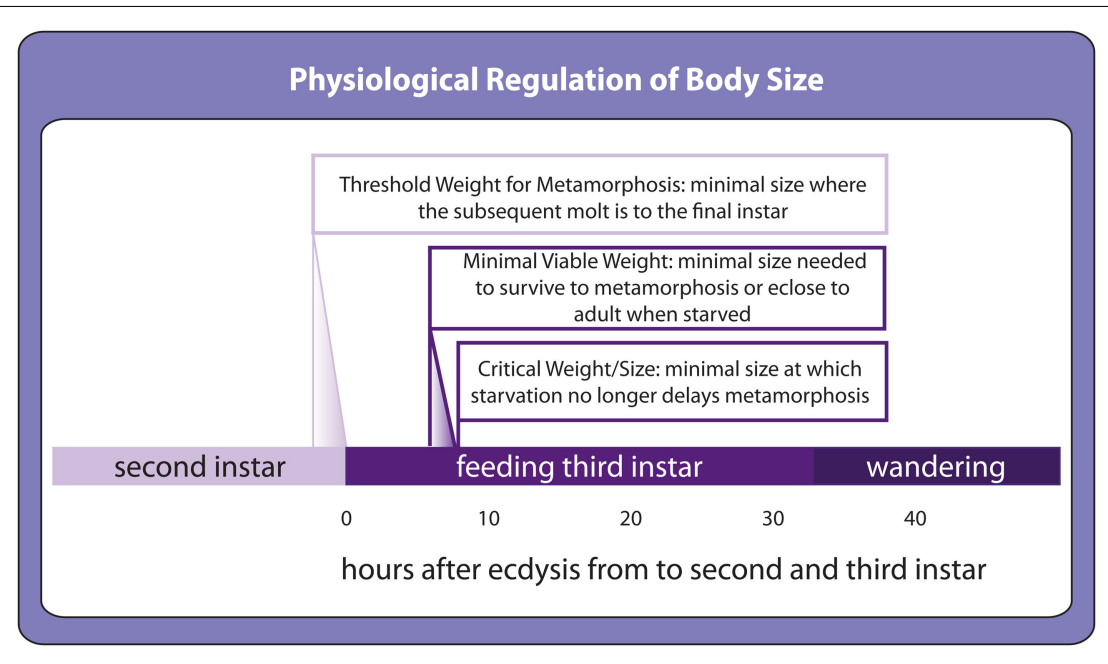

FIGURE 3 | Environmentally sensitive developmental thresholds in the second and third instar as defined in Drosophila. Toward the end of the second instar, a size-dependent threshold called threshold size for metamorphosis determines whether the following molt will be the final larval molt before metamorphosis. The precise timing for this event has not yet been determined. At the beginning of the third instar, environmentally sensitive thresholds control the transition to metamorphosis. Minimal viable weights for pupariation and eclosion are the minimal sizes above which larvae can survive starvation to metamorphose and to eclose to adults respectively. Critical weight, also referred to as critical size, is the minimal size at which the onset of metamorphosis can no longer be delayed by starvation. 
timing of metamorphosis: larvae that lack corpora allata show a slight developmental delay rather then precocious metamorphosis (Riddiford et al., 2010). JH does, however, reduce final body size, presumably by reducing growth rate (Riddiford et al., 2010).

In Drosophila, ecdysone plays a central role in regulating critical weight. In the third and final instar, three small peaks of ecdysone prepare the larva for the onset of metamorphosis (Warren et al., 2006). The first of these peaks reaches its maximum at around $8 \mathrm{~h}$ after the molt from second to third instar (Warren et al., 2006) around the same time as critical weight is attained (Mirth et al., 2005). For this reason, this peak has come to be known as the critical weight ecdysone peak.

As discussed above, starving larvae before they reach critical weight delays their development. The same is true for systemic suppression of the insulin signaling pathway (Shingleton et al., 2005). Thus attainment of critical size appears to be insulin dependent. Additional data indicate that insulin/TOR signaling in the prothoracic gland regulates the critical weight transition. Hyperactivating insulin signaling specifically in the prothoracic gland causes larvae to reach critical weight prematurely (Caldwell et al., 2005; Colombani et al., 2005; Mirth et al., 2005). Conversely, repressing insulin or TOR signaling in the prothoracic gland delays development and the onset of metamorphosis (Layalle et al., 2008; Mirth et al., 2009).

Insulin/TOR signaling in the prothoracic gland induces these developmental delays under poor nutritional conditions presumably by reducing ecdysone synthesis (Colombani et al., 2005; Mirth et al., 2005) during the critical weight ecdysone peak. Evidence for this comes from studies of the effects of nutrition on patterning in the imaginal disks. Starving pre-critical weight larvae delays the expression of patterning gene products such as Wingless, Senseless, and Cut in the wing disks (Mirth et al., 2009). Post-critical weight larvae continue patterning their disks when starved.

Ecdysone exerts its action by binding to the functional ecdysone receptor $(\mathrm{EcR})$, a heterodimer of EcR and Ultraspiracle (Usp; Koelle et al., 1991; Yao et al., 1992). The EcR/Usp heterodimer activates the transcription of target genes in the presence of ecdysone and represses transcription in its absence (Schubiger and Truman, 2000; Cherbas et al., 2003; Hu et al., 2003; Schubiger et al., 2005; Brown et al., 2006). Knocking down either EcR or Usp eliminates the repressive action of the functional EcR, thereby partially mimicking ecdysone action (Schubiger and Truman, 2000; Cherbas et al., 2003; Hu et al., 2003; Schubiger et al., 2005; Brown et al., 2006; Mirth et al., 2009). Either activating insulin signaling in the prothoracic gland or knocking down EcR specifically in the imaginal disks of starved pre-critical weight larvae allows the wing disks to continue patterning (Mirth et al., 2009). These data have been used to demonstrate that starvation, via the insulin/TOR pathway, reduces ecdysone synthesis at critical weight thereby delaying development. How insulin/TOR signaling affects the two remaining ecdysone peaks has not yet been determined and would identify whether these peaks regulate developmental events that also depend on nutrition.

Up- or down-regulating the PTTH/RAS/MAPK pathway in the prothoracic gland also affects the timing of ecdysone synthesis and the onset of metamorphosis (Caldwell et al., 2005). In Drosophila, PTTH/RAS/MAPK signaling in the prothoracic gland is activated when PTTH binds to its receptor Torso (Rewitz et al., 2009). Like lepidopterans, Drosophila larvae also synthesize PTTH in neurosecretory cells in the brain, and ablation of these cells leads to a substantial developmental delay, in part caused by a delay in the attainment of critical weight (McBrayer et al., 2007; Ou et al., 2011). Intriguingly, PTTH transcription in Drosophila shows a cyclical profile with a periodicity of $\sim 8 \mathrm{~h}$ (McBrayer et al., 2007; Ou et al., 2011). Larvae that are mutant for a component of the circadian clock, pigment dispersion factor, show disrupted periodicity in PTTH transcription (McBrayer et al., 2007). This suggests that PTTH may impose some circadian control over ecdysone synthesis, which echoes its role in lepidopterans where PTTH is released in a photo-dependent manner after attainment of critical weight (Nijhout and Williams, 1974a). Further, PTTH transcription is also regulated by the development of the imaginal disks. Damage to the disks causes a delay in development and the attainment of critical weight, in part through a suppression of PTTH synthesis (Halme et al., 2010). Taken together, PTTH integrates circadian cues and cues from the developing imaginal tissues to regulate ecdysone synthesis.

Thus the synthesis of ecdysone at critical weight is regulated by at least two signaling pathways in Drosophila, each pathway possibly providing different sources of information: the insulin/TOR signaling pathway providing information about the nutritional status of the larva and the PTTH/RAS/MAPK pathway providing temporal information and information about the developmental status of the imaginal disks. We do not yet understand how information is integrated by the two pathways. Potentially, insulin/TOR- and PTTH-signaling may control ecdysone synthesis at the critical weight transition in an additive manner. Reducing insulin/TOR signaling in the prothoracic gland before critical weight causes a developmental delay but does not prevent metamorphosis (Caldwell et al., 2005; Mirth et al., 2005; Layalle et al., 2008). Similarly ablation of the PTTH-producing cells also delays but does not prevent metamorphosis (McBrayer et al., 2007). By down-regulating one pathway, the other pathway may compensate, but requires more time to do so.

Alternatively, insulin/TOR and PTTH-signaling may interact synergistically, with signaling through one pathway enhancing signaling through the other. Some evidence for this comes from studies of the silkworm Bombyx mori, where applying Wortmannin, a drug that inhibits phosphatidylinositol-3 kinase (Powis et al., 1994) an important component in the insulin signaling pathway, greatly reduces the levels of PTTH-stimulated ecdysone synthesis (Gu et al., 2011). In addition, recent research in Drosophila has hinted at how integration may be regulated molecularly: transforming growth factor (TGF) $\beta$ /Activin signaling mediates the response to both PTTH and dILPs by regulating the expression of both the PTTH receptor, Torso, and the dILP receptor, InR, in the prothoracic gland cells (Gibbens et al., 2011). Further, PTTH/RAS/MAPK signaling regulates the expression of Inr (Zhang et al., 2008), and so may sensitize the prothoracic gland to nutritional signaling via the insulin/TOR signaling pathway. Together, these results will allow us to test whether PTTH/RAS/MAPK and insulin/TOR signaling act additively or synergistically to control the critical weight ecdysone peak. 
Work in the last year has identified an additional factor regulating critical weight in Manduca. This research shows that caterpillars reach critical weight when their fixed tracheal volume begins to limit oxygen transfer to the body's growing tissues (Callier and Nijhout, 2011). Rearing larvae in hypoxic conditions induces earlier critical weight transitions, and rearing them in hyperoxic conditions induces delayed transitions (Callier and Nijhout, 2011). These results have led Callier and Nijhout to conclude that oxidative stress regulates ecdysone synthesis to control critical weight, possibly via the hypoxia inducible factor-1 (HIF1) pathway, the canonical oxygen-sensing signaling pathway in all animals (Figure 4; Hampton and Peet, 2009). Whether HIF-1 signaling influences ecdysone synthesis directly or via insulin/TOR or PTTH or some other pathway is unclear, although in mammalian cells the HIF-1 and insulin/TOR signaling pathways have been shown to interact (Yu et al., 2012).

Collectively, these data suggest that the critical weight transition is regulated by multiple signaling pathways each integrating a set of environmental cues to impact ecdysone synthesis itself (Figure 4). These pathways may work together to initiate timely metamorphosis only when a larvae has stored sufficient nutrients to complete development to adulthood, when it has outgrown its tracheal system, when its organs are at the correct developmental stage, and at the appropriate time of day (larvae tend to begin metamorphosis during the night; Roberts et al., 1987). This hypothesis remains to be tested. Furthermore, although this model relates principally to the regulation of critical weight, it provides a framework for understanding other environmentally dependent developmental transitions. Transitions such as the minimal viable weight and threshold weight for metamorphosis are also likely to involve signaling pathways responsive to multiple environmental cues. Like critical weight, they are likely to regulate or be regulated by insulin/TOR and the ecdysone-signaling cascades.

\section{GENETIC REGULATION OF BODY SIZE: LESSONS FROM COMPARISONS OF EXPERIMENTAL EVOLUTION AND DEVELOPMENTAL PLASTICITY}

In addition to variation induced by environmental factors, body size also varies between species, populations, or sexes as a result of genetic differences. Decades of studies of wild populations of Drosophila show that size increases with increasing latitude and altitude, a pattern repeated across continents called clinal variation in body size (James and Partridge, 1995; James et al., 1995; Robinson and Partridge, 2001; de Jong and Bochdanovits, 2003). This geographical feature of body size appears to be under strong selection. Ten years after Drosophila subobscura was introduced to North America, they showed no clinal variation (Huey et al., 2000). Twenty years after introduction, this species developed a structure of clinal variation with latitude similar to the ancestral populations (Huey et al., 2000). This raises the question: what are the developmental mechanisms targeted by selection that result in the variation in body size seen across latitudes and altitudes?

One method to answer this question is to identify the sizeregulatory mechanisms that have been targeted by selection on adult body size in artificial selection and experimental evolution experiments. In general, selection for a change in body size results in a change in the duration of larval growth rather than a change in larval growth rate (Reeve, 1954; Robertson, 1963; Hillesheim and Stearns, 1992; Partridge and Fowler, 1993; Partridge et al., 1999). In at least one of these experiments (Partridge et al., 1999), the

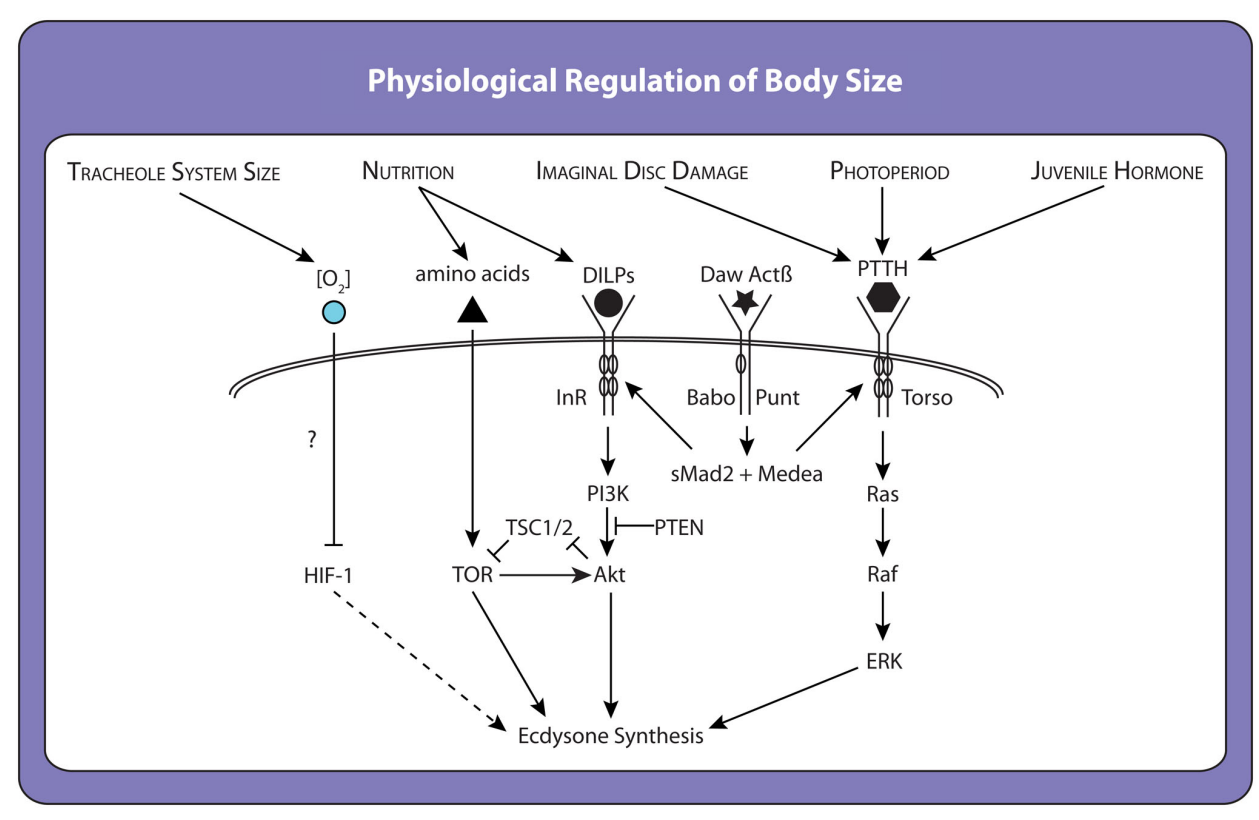

FIGURE 4 | Factors and molecular mechanisms that influence ecdysone synthesis and the timing of critical weight attainment. Many

environmentally sensitive pathways act to regulate the ecdysone synthesis pathway in a redundant manner. When one environmental signal is perturbed, another pathway steps in and allows pupariation, albeit with a delay. For example, starving larvae before they reach critical weight causes a delay because the prothoracic gland must rely on other inputs to initiate ecdysone synthesis. However, once ecdysone synthesis has been initiated it is irreversible. Thus, critical weight represents a switch rather than the maintenance of a state. 
increase in the duration of development was associated with an increase in the minimal viable weight for pupariation, which in Drosophila correlates with the critical weight (Stieper et al., 2008). Similarly in Manduca, accidental selection for large caterpillars over 30 years of laboratory culture resulted in an increase in body size due, in part, to increased critical weight (D'Amico et al., 2001). Thus selection for an increase or decrease in body size may target the mechanisms that regulate critical weight.

A second approach has been to evolve laboratory populations of Drosophila in environmental conditions that mimic those that vary across latitudinal and altitudinal clines, specifically temperature (which decreases with latitude and altitude) and oxygen level (which decreases with altitude). Cold-adapted Drosophila are larger than warm-adapted animals when reared at the same temperature (Figure 5; Partridge et al., 1994; James and Partridge, 1995; Bochdanovits and de Jong, 2003). Conversely hypoxiaadapted Drosophila are smaller relative to norm- and hyperoxiaadapted Drosophila when reared at the same oxygen level (Zhou et al., 2007, 2011; Klok and Harrison, 2009). The fact that low levels of oxygen tend to select for smaller flies suggests that the altitudinal cline in body size is likely an evolved response to temperature.

In the case of both temperature and oxygen evolved responses, the evolved response on body size occurs in the same direction as the plastic response. For any single genotype, rearing larvae at lower temperatures generates larger adults (Figure 5; Partridge et al., 1994; Nunney and Cheung, 1997; French et al., 1998; Shingleton et al., 2009), echoing the evolved response. Similarly, for any single genotype, rearing larvae at lower oxygen levels generates smaller adults (Peck and Maddrell, 2005).
Because the evolved and plastic responses to changes in temperature show similar effects on body size, this suggests that the evolution of body size results from selection on the mechanisms underlying the plastic response. However, the evolved and plastic responses do not appear to be controlled by the same mechanisms. The plastic response to decreased temperature is due to an increase in developmental time (James et al., 1997) and a decrease in larval growth rate (Ray, 1960). In contrast, the evolved response to temperature is the reverse: cold-adapted flies have a decreased developmental time and an increased growth rate compared to warm-adapted flies when reared at the same temperature (Partridge et al., 1994). Nevertheless, in both cold-adapted flies and non-adapted flies reared at low temperatures, the increase in body size appears to be correlated with an increase in the efficiency with which they convert a fixed amount of food into adult tissue (Robinson and Partridge, 2001). The plastic and evolved responses to temperature may appear to differ because we have yet to identify the correct environmentally induced developmental response under selection. This highlights the need to understand how different environmental conditions regulate body size at the level of genetic and physiological mechanisms, and the need to understand which of these mechanisms change to produce the evolved responses in body size.

A number of studies have directly addressed the genetic underpinning of size variation. A familiar example, the impressive variation in body size seen in breeds of dog is mostly due to allelic variation of the insulin-like growth factor-1 gene (Sutter et al., 2007). In addition, a recent study comparing two species of jewel wasp, Nasonia vitripennis and $N$. giraulti, show that a male-specific difference in wing size and shape results from differences in the

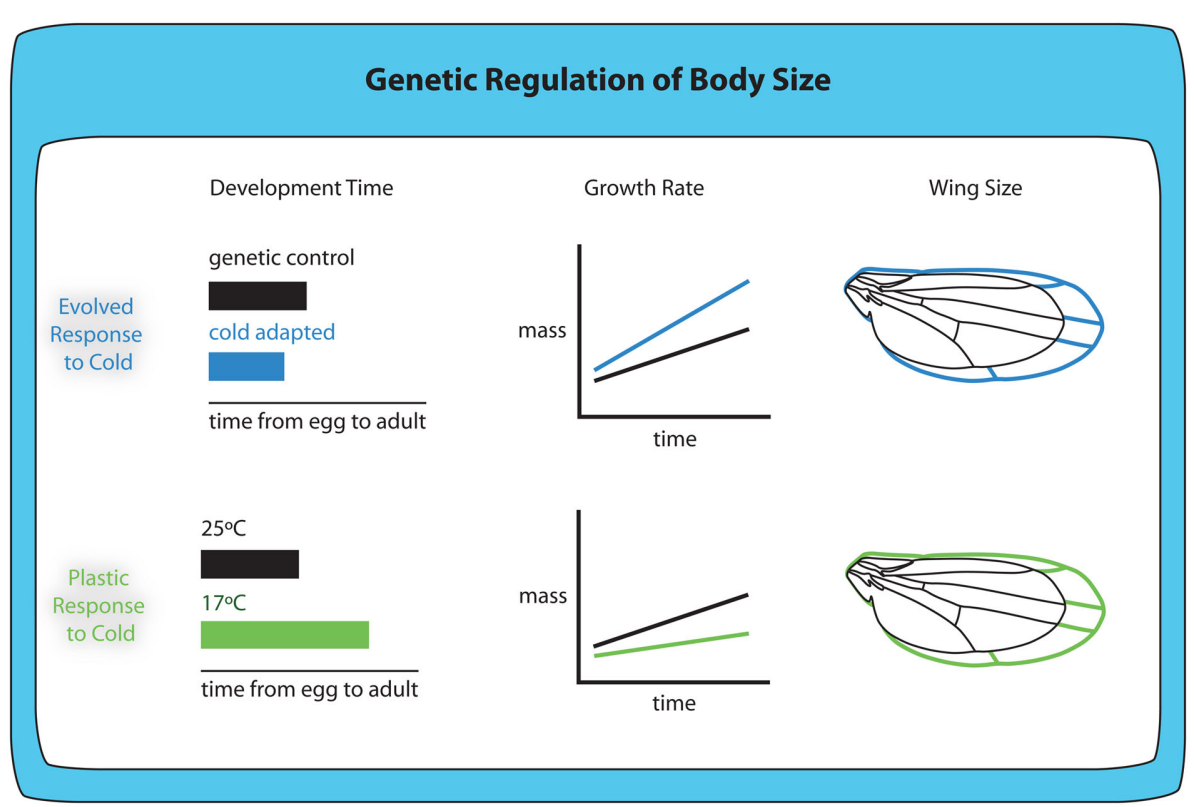

FIGURE 5 | Evolved and plastic responses to cold temperature produce larger animals with different size-related phenotypes. Cold-adapted flies show shorter development times, increased growth rate and larger body and wing size when reared at the same temperature as non-adapted flies. Although the plastic response to cold temperature includes larger body and wing size, larvae raised at colder temperatures $\left(17^{\circ} \mathrm{C}\right)$ show increased development time and reduced growth rates. 
expression of unpaired, a ligand of the JAK/STAT stress signaling pathway (Loehlin and Werren, 2012). Both results suggest that the genetic component of size variation results from selection on the mechanisms underlying the responses to environmental conditions. Further work in other organisms will clarify if this is a general pattern.

In Drosophila, studies of quantitative trait loci reveal that clinal variation in body size associates with cosmopolitan chromosome inversions. The frequency of two inversions in particular associate with latitudinal clines in Africa, Europe, South America, and Australia, $\operatorname{In}(2 \mathrm{~L}) \mathrm{t} / \mathrm{In}(2 \mathrm{~L}) \mathrm{NS}$ (van't Land et al., 2000) and $\operatorname{In}(3 \mathrm{R}) \mathrm{P} / \mathrm{In}(3 \mathrm{R}) \mathrm{K}$ (Weeks et al., 2002). These inversions contain many genes involved in metabolism and insulin/TOR signaling hinting that variation in insulin/TOR signaling could underlie the genetic differences between populations (de Jong and Bochdanovits, 2003).

Although these correlations appear promising, to date researchers have not directly linked the activity of insulin/TOR or other genes controlling metabolism with differences in body size in natural populations of Drosophila. The fact that these inversions associate with latitudinal size clines might suggest that they contain complexes of co-adapted genes that result in population differences (Caceres et al., 1997, 1999). A more recent study indicates that hundreds of loci were targeted by selection to increase or decrease Drosophila body size over 30 generations, suggesting that body size variation in Drosophila is very polygenic (Turner et al., 2011). Nevertheless, as discussed above, direct selection on body size may target very different size-regulatory mechanisms than indirect selection, for example via thermal-adaptation. A careful analysis of the growth and developmental features of these genetic variants compared to what we know about how hormones affect growth and developmental timing would shed invaluable insight on the genetics of body size.

\section{COORDINATION OF ORGAN GROWTH: INTEGRATING WHOLE BODY AND ORGAN-SPECIFIC SIGNALS}

Thus far, this review has concentrated on the physiological-genetic mechanisms that regulate body size in Drosophila and how variation in these mechanisms underlies genetic and environmental variation in body size. Implicit in these mechanisms is that variation in body size is accompanied by variation in the size of individual organs that constitute the whole body. After all, the maintenance of "correct" body proportions across a range of body sizes is essential to the maintenance of an animal's form and function. Nevertheless, how growth is coordinated among organs to generate a properly proportioned organism is only now being elucidated.

To a certain extent, the coordination of organ growth appears to be regulated by the common exposure of growing tissues to circulating growth regulators released from central endocrine organs. For example, a reduction in developmental nutrition results in a coordinated decrease in organ growth through a reduction in the level of circulating dILPs and tissue-specific suppression of the insulin signaling pathway (Brogiolo et al., 2001; Rulifson et al., 2002). However, although some organs, like the wing and eye disks of Drosophila, show significantly reduced growth in poorly fed larvae, other organs are remarkably constant in their body size across nutritional conditions. The size of the genital disks (Shingleton et al., 2005) and the CNS (Cheng et al., 2011) are far less affected by poor nutrition. The genital disks resist changes in size due to poor nutrition by expressing low levels of a negative regulator of insulin signaling, FOXO (Tang et al., 2011). In the CNS, the glial cells produce a secreted protein, Anaplastic Lymphoma Kinase, that activates the insulin signaling pathway to stimulate growth of the neuroblasts and their progeny even under starvation conditions (Cheng et al., 2011). These studies illustrate two mechanisms that allow organ growth to be spared across environmental conditions. We would expect these types of mechanisms to act whenever there was a strong relationship between organ size and the fitness of the animal carrying the organ.

Common exposure to growth regulators produced from central endocrine organs appears to be essential for coordinating organ growth and development in response to external perturbations in growth, such as reduced developmental nutrition. However, they are insufficient to coordinate organ growth and development when the perturbation is internal and restricted to an individual organ. In order for developmental systems to cope with localized growth perturbation, the growth-perturbed tissue must be able to recognize its condition and signal it to other organs in the body. This appears to be the case in Drosophila. As mentioned above, larvae with damaged wing disks delay attainment of critical weight, presumably to allow additional developmental time for disk repair (Simpson et al., 1980; Stieper et al., 2008; Halme et al., 2010). Intriguingly, however, undamaged disks do not overgrow during this extended developmental period (Parker and Shingleton, 2011). This is because they slow their growth to match that of the growth-perturbed wing disk (Parker and Shingleton, 2011). Thus damaged disks appear to recognize their condition and generate a signal that retards both development and growth.

It is unclear precisely how this is achieved, although there are some intriguing clues as to the mechanism. The damaged wings appear to recognize their condition through activation of the apoptosis machinery, possibly via JNK signaling and p53. JNK signaling and p53 work together to regulate stress-induced apoptosis (Morata et al., 2011). Blocking JNK signaling prevents regeneration of damaged tissue (Bosch et al., 2005; Bergantiños et al., 2010), while blocking p53 prevents the coordinated non-autonomous growth retardation of surrounding tissue (Mesquita et al., 2010). Both phenomena may reflect an inhibition of a developmentand growth-retarding signal (or signals) produced by a damaged disk. This signal (or signals) is currently unknown, although one candidate is Neural Lazarillo (NLaz), a JNK-regulated secreted protein that when expressed in the fat body suppresses larval growth by antagonizing insulin signaling (Hull-Thompson et al., 2009). The signal from the damaged imaginal disks also suppresses ecdysone synthesis, in part by retarding the production of PTTH in a retinoid-dependent manner (Halme et al., 2010; Figure 6). Importantly, whilst application of ecdysone rescues the developmental delay observed in larvae with damaged wing disks, it also rescues growth of the non-growth-perturbed disks (Parker and Shingleton, 2011). It appears, therefore, that ecdysone is limiting for developmental progression and organ growth when the wing disk is growth-perturbed. 


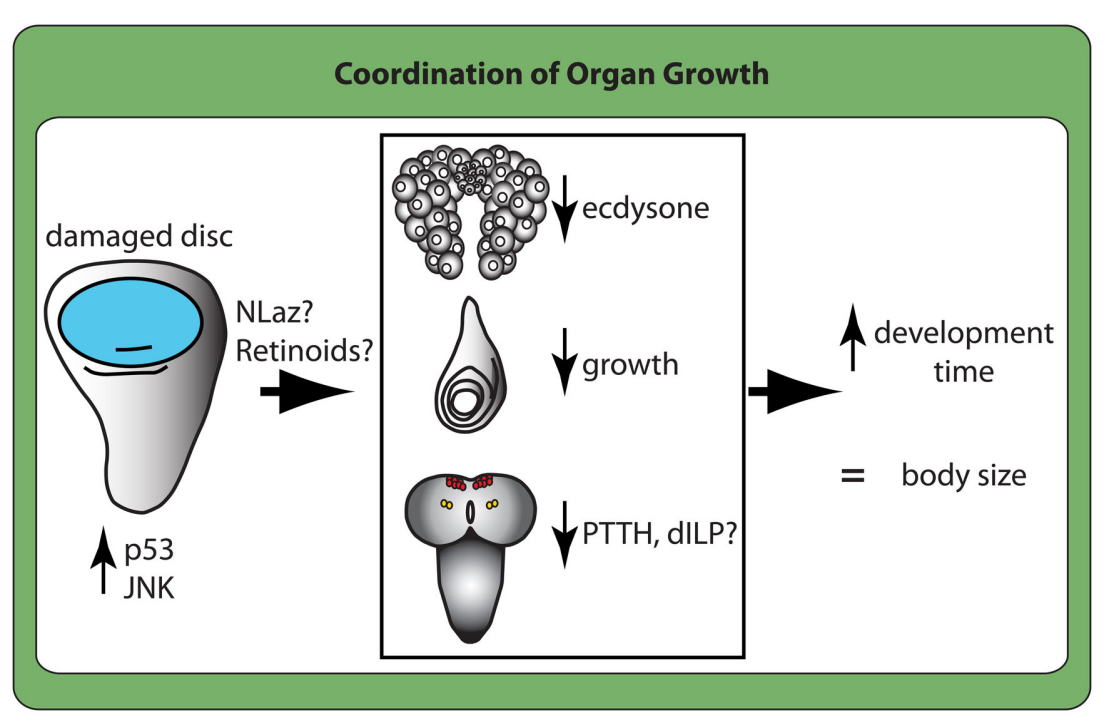

FIGURE 6 | Damaged or slow-growing disks signal to the other tissues to reduce their growth and prolong development. Damaged or slow-growing disks signal their status within the tissue by upregulating stress signaling via the JNK pathway and the apoptotic machinery protein $\mathrm{p53}$. They signal their slow growth to the rest of the body, at least in part, through retinoid signaling and potentially through Neural Lazarillo (NLaz). This reduces ecdysone synthesis by the prothoracic gland (top tissue in box), reduces growth of another normally growing disks (leg disk in middle), and reduces PTTH (PTTH cells in yellow) and may reduce the production of insulin like peptides (dILP) from the insulin producing cells (in red) in the brain (bottom tissue). In this manner, growth-perturbed disks delay development although the larvae eventually metamorphose to produce normally sized adults.
These data indicate that ecdysone not only regulates the timing of developmental events, but also imaginal disk growth. Suppressing ecdysone synthesis results in large larvae with disproportionately small wing disks (Mirth et al., 2009). Thus, if systemic growth retardation in larvae with a damaged disk is due to a suppression of insulin signaling, possibly via NLaz, the application of ecdysone may rescue growth by allowing the remaining disks to grow in an insulin-independent manner. If this scenario is correct, insulin signaling acts on the prothoracic gland to regulate ecdysone synthesis, and ecdysone, in turn, feeds back to control insulin synthesis by the insulin producing cells.

Ecdysone regulates the growth of imaginal tissues in insects other than Drosophila. In Manduca, most of the growth of the wing imaginal disks occurs in the wandering phase, after larval body growth is complete (Nijhout and Grunert, 2002; Nijhout et al., 2007). Nijhout and Grunert (2010) found both that the rate and duration of wing disk growth depends on the amount of growth in the larval body (Nijhout and Grunert, 2010). Furthermore, they found that the growth of the larval body during the feeding stage correlates with the concentration and duration of ecdysone secretion at wandering (Nijhout and Grunert, 2010). Thus ecdysone appears to play a role in regulating proportional growth in Drosophila and Manduca. In Manduca, the amount of ecdysone synthesized during the wandering stage could potentially be controlled by the amount of dILP6 produced by the fat body (Okamoto et al., 2009; Slaidina et al., 2009; Chell and Brand, 2010), as a measure of stored nutrient load.

We are a long way from fully understanding how the size and shape of organs is determined. Nevertheless, recent advances provide us with clues as to how organs might regulate their sensitivity to environmental conditions by regulating insulin/TOR signaling independent of nutrition. From parallel work, ecdysone is emerging as a key hormone integrating the growth of organs with each other and with the body as a whole. This suggests that integration between insulin/TOR- and ecdysone-signaling is more complex than originally surmised. Moreover, the interaction between these two pathways allows them to direct the larvae through environmentally dependent developmental transitions while ensuring that organ growth and development remain integrated.

\section{ADDITIONAL REGULATORS OF ORGAN SIZE: INTEGRATING ORGAN-AUTONOMOUS WITH SYSTEMIC GROWTH REGULATORS}

The above discussion suggests that we have a good, and improving, understanding of how the different regulators of growth rate and duration are integrated physiologically to determine final body and organ size. However, there are many known regulators of organ growth whose influence on growth at the organismal level is unknown. Two regulators that warrant specific mention are patterning genes and the Hippo pathway.

Patterning genes are short-range paracrine signals (morphogens) and the signaling pathways that produce and respond to them (Edgar, 2006). They define the position and size of specific tissue types within an organ, for example the position of veins in a Drosophila wing and the size of the intervein region (Lecuit and Le Goff, 2007). Consequently, patterning genes are also regulators of overall organ size, and changes in their expression or activity can increase or decrease the size of an organ (Day and Lawrence, 2000; Crickmore and Mann, 2006; de Navas et al., 2006). In controlling the pattern and shape of a particular organ patterning genes must also regulate and/or be regulated by other processes that control size. After all, the reduction in leg size in malnourished flies is not 
through a reduction in the number of leg segments, but because all the segments are proportionally smaller. However, the mechanisms that maintain pattern across an environmental range of organ sizes have yet to be elucidated.

The recently discovered Hippo signaling pathway is also a known regulator of organ size (Bennett and Harvey, 2006; Dong et al., 2007; Pan, 2007). The pathway comprises two large atypical cadherins, Fat and Dachsous (Ds), that sit on the cell membrane (Sopko et al., 2009). Interactions between Fat and Ds in neighboring cells activates the former and initiates a signal transduction cascade that includes Hippo and Warts and that ultimately suppresses the activity of the transcription factor Yorkie, a growth promoter (Halder and Johnson, 2011).

Although the key components of the Hippo pathway have been well elucidated, its biological function during development is poorly understood. One function appears to be the regulation of growth in response to cell density, suppressing growth when cell density is high (Varelas and Wrana, 2011). This may function to stop an organ's growth when it reaches a particular size and particular cellular density (Shingleton, 2010). It also appears that the Hippo signaling pathway integrates information from multiple signaling pathways that regulate growth and development (Grusche et al., 2010). Intriguingly, regulators of Hippo signaling include the patterning gene decapentaplegic (Dpp; Rogulja et al., 2008) and scalloped (Sd; Goulev et al., 2008; Zhang et al., 2008), linking Hippo signaling with the mechanisms that regulate organ pattern. Further, Yorkie is activated by apoptosis via JNK signaling (Sun and Irvine, 2011), which may link Hippo signaling to the mechanisms that coordinate growth among organs. Finally, Hippo signaling is also regulated by the gene lethal giant larvae (lgl; Grzeschik et al., 2011), mutations of which also cause developmental delay and, likely, systemic suppression of organ growth. However, the extent to which organ-autonomous Hippo-regulated growth is regulated by and regulates systemic physiological growth regulators remains unknown.

\section{A SYNTHETIC VIEW OF BODY SIZE}

Adult body size results from both genetic and environmental signals that regulate specific stages of development to control growth rate and the duration of the growth period. These signals are tightly tuned to ensure that organ and overall growth are coordinated

\section{REFERENCES}

Bai, X., Ma, D., Liu, A., Shen, X., Wang, Q. J., Liu, Y., and Jiang, Y. (2007). Rheb activates mTOR by antagonizing its endogenous inhibitor, FKBP38. Science 318, 977-980.

Beadle, G. W., Tatum, E. L., and Clancy, C. W. (1938). Food level in relation to rate of development and eye pigmentation in Drosophila melanogaster. Biol. Bull. 75, 447-462.

Bennett, F. C., and Harvey, K. F. (2006). Fat cadherin modulates organ size in Drosophila via the Salvador/Warts/Hippo signaling pathway. Curr. Biol. 16, 2101-2110.
Bergantiños, C., Corominas, M., and Serras, F. (2010). Cell deathinduced regeneration in wing imaginal discs requires JNK signalling. Development 137, 1169-1179.

Bochdanovits, Z., and de Jong, G. (2003). Experimental evolution in Drosophila melanogaster: interaction of temperature and food quality selection regimes. Evolution 57, 1829-1836.

Bosch, M., Serras, F., Martín-Blanco, E., and Baguñà, J. (2005). JNK signaling pathway required for wound healing in regenerating Drosophila wing imaginal discs. Dev. Biol. 280, 73-86.

to produce the fittest functional adult given the environmental conditions. Although we have come a long way in our understanding of how this coordination is achieved, much still needs to be learned.

Perhaps the ultimate goal in understanding the mechanisms of size control is to be able to precisely predict, given the genetic profile and the rearing conditions of a larva, the final size and proportions of the emerging adult. We are far from being able to make such predictions. Up until recently, extensive work on size regulation produced a catalog of apparently unrelated factors all known to influence body and organ size in Drosophila: insulin/TOR signaling, ecdysone, cell cycle regulators, rearing temperature, latitude, patterning genes, Hippo signaling, etc. Whilst it is obvious that a developing Drosophila larva must be integrating these various factors to regulate its final body size, it is not at all clear how this integration is achieved.

Regulators of body size do not act additively. The effects of a genetic mutation in a growth regulating pathway is unlikely to have uniform effects across environmental conditions, while environmental changes in body size will vary from genotype to genotype. We propose that an important first step to a more complete understanding of size control is to connect the hormonal mechanisms that regulate the rate and duration of growth with the molecular-genetic mechanisms that control the production of, and the response to, these hormones at a tissue-specific level. The insulin/TOR regulation of ecdysone in the prothoracic gland is one example of this type of connection. However, we know there are other connections to be elucidated: How does insulin/TOR signaling in the fat body control the release of dILPs from the brain? How do growth-perturbed organs signal their condition to the prothoracic gland to inhibit ecdysone synthesis? How is ecdysone synthesis regulated by hypoxia? These are just the connections we know about. There are likely connections that have yet to be discovered.

We envisage that the result of these studies will be the construction of a regulatory network that extends beyond the generegulatory networks, signaling pathways, and hormone cascades that we are familiar with, but that incorporates the spatial and temporal dynamics of development. Such a network will have enormous utility in understanding organismal variation in body and organ size, due to evolution, the environment and disease.

Britton, J. S., and Edgar, B. (1998). Environmental control of the cell cycle in Drosophila: nutrition activates mitotic and endoreplicative cells by distinct mechanisms. Development 125, 2149-2158.

Brogiolo, W., Stocker, H., Ikeya, T., Rintelen, F., Fernandez, R., and Hafen, E. (2001). An evolutionarily conserved function of the Drosophila insulin receptor and insulin-like peptides in growth control. Curr. Biol. 11, 213-221.

Brown, H. L. D., Cherbas, L., Cherbas, P., and Truman, J. W. (2006). Use of time-lapse imaging and dominant negative receptors to dissect the steroid receptor control of neuronal remodeling in Drosophila. Development 133, 275-285.

Caceres, M., Barbadilla, A., and Ruiz, A. (1997). Inversion length and breakpoint distribution in the Drosophila buzzatii species complex: is inversion length a selected trait? Evolution 51, 1149-1155.

Caceres, M., Barbadilla, A., and Ruiz, A. (1999). Recombination rate predicts inversion size in Diptera. Genetics 153, 251-259.

Caldwell, P. E., Walkiewicz, M., and Stern, M. (2005). Ras activity in the Drosophila prothoracic gland regulates body size and developmental rate via ecdysone release. Curr. Biol. 15, 1785-1795. 
Callier, V., and Nijhout, H. F. (2011). Control of body size by oxygen supply reveals size-dependent and size-independent mechanisms of molting and metamorphosis. Proc. Natl. Acad. Sci. U.S.A. 108, 14664-14669.

Chell, J. M., and Brand, A. H. (2010). Nutrition-responsive glia control exit of neural stem cells from quiescence. Cell 143, 1161-1173.

Cheng, L. Y., Bailey, A. P., Leevers, S. J., Ragan, T. J., Driscoll, P. C., and Gould, A. P. (2011). Anaplastic lymphoma kinase spare organ growth during nutrient restriction in Drosophila. Cell 146, 435-447.

Cherbas, L., Hu, X., Zhimulev, I., Belyaeva, E., and Cherbas, P. (2003). EcR isoforms in Drosophila: testing tissue-specific requirements by targeted blockade and rescue. Development 130, 271-284.

Colombani, J., Bianchini, L., Layalle, S., Pondeville, E., Dauphin-Villemant, C., Antoniewski, C., Carre, C., Noselli, S., and Leopold, P. (2005). Antagonistic actions of ecdysone and insulins determine final size in Drosophila. Science 310, 667-670.

Colombani, J., Raisin, S., Pantalacci, S., Radimerski, T., Montagne, J., and Léopold, P. (2003). A nutrient sensor mechanism controls Drosophila growth. Cell 114, 739-749.

Crickmore, M. A., and Mann, R. S. (2006). Hox control of organ size by regulation of morphogen production and mobility. Science 313, 63-68.

D'Amico, L. J., Davidowitz, G., and Nijhout, H. F. (2001). The developmental and physiological basis of body size evolution in an insect. Proc. Biol. Sci. 268, 1589-1593.

Day, S. J., and Lawrence, P. A. (2000). Measuring dimensions: the regulation of size and shape. Development 127, 2977-2987.

de Jong, G., and Bochdanovits, Z. (2003). Latitudinal clines in Drosophila melanogaster: body size, allozyme frequencies, inversion frequencies and the insulin-signalling pathway. J. Genet. 82, 207-223.

de Navas, L. F., Garaulet, D. L., and Sanchez-Herrero, E. (2006). The Ultrabithorax Hox gene of Drosophila controls haltere size by regulating the Dpp pathway. Development 133, 4495-4506.

DiAngelo, J. R., Bland, M. L., Bambina, S., Cherry, S., and Birnbaum, M. M. (2009). The immune response attenuates growth and nutrient storage in Drosophila by reducing insulin signaling. Proc. Natl. Acad. Sci. U.S.A. 106, 20853-20858.
Dominick, O. S., and Truman, J. W. (1985). The physiology of wandering behavior in Manduca sexta. 2. The endocrine control of wandering behavior. J. Exp. Biol. 117, 45-68.

Dong, J., Feldmann, G., Huang, J., Wu, S., Zhang, N., Comerford, S. A., Gayyed, M. F., Anders, R. A., Maitra, A., and Pan, D. (2007). Elucidation of a universal size-control mechanism in Drosophila and mammals. Cell 130, 1120-1133.

Edgar, B. A. (2006). How flies get their size: genetics meets physiology. Nat. Rev. Genet. 7, 907-916.

French, V., Feast, M., and Partridge, L. (1998). Body size and cell size in Drosophila: the developmental response to temperature. J. Insect Physiol. 44, 1081-1089.

Gao, X., and Pan, D. (2001). TSC1 and TSC2 tumor suppressors antagonize insulin signaling in cell growth. Genes Dev. 15, 1383-1392.

Gao, X., Zhang, Y., Arrazola, P., Hino, O., Kobayashi, T., Yeung, R. S., Ru, B., and Pan, D. (2002). Tsc tumor suppressor proteins antagonize aminoacid-TOR signaling. Nat. Cell Biol. 4 , 699-704.

Garami, A., Zwartkruis, F. J. T., Nobukuni, T., Joaquin, M., Roccio, M., Stocker, H., Kozma, S. C., Hafen, E., Bos, J. L., and Thomas, G. (2003). Insulin activation of Rheb, a mediator of $\mathrm{mTOR} / \mathrm{S} 6 \mathrm{~K}, 4 \mathrm{E}-\mathrm{BP}$ signaling is inhibited by TSC 1 and 2 mole. Cell 11, 1457-1466.

Géminard, C., Rulifson, E. J., and Léopold, P. (2009). Remote control of insulin secretion by fat cells in Drosophila. Cell Metab. 10, 199-207.

Gibbens, Y. Y., Warren, J. T., Gilbert, L. I., and O'Connor, M. B. (2011). Neuroendocrine regulation of Drosophila metamorphosis requires TGF/Activin signaling. Development 138, 2693-2703.

Gilbert, L. I., Rybczynski, R., and Warren, J. T. (2002). Control and biochemical nature of the ecdysteroidogenic pathway. Annu. Rev. Entomol. 47, 883-912.

Goulev, Y., Fauny, J. D., Gonzalez-Marti, B., Flagiello, D., Silber, J., and Zider, A. (2008). SCALLOPED interacts with YORKIE, the nuclear effector of the hippo tumor-suppressor pathway in Drosophila. Curr. Biol. 18, 435-441.

Grusche, F. A., Richardson, H. E., and Harvey, K. F. (2010). Upstream regulation of the hippo size control pathway. Curr. Biol. 20, R574-R582.

Grzeschik, N. A., Parsons, L. M., Allott, M. L., Harvey, K. F., and Richardson, H. E. (2011). Lgl, aPKC, and Crumbs regulate the Salvador/Warts/Hippo pathway through two distinct mechanisms. Curr. Biol. 20, 573-581.

Gu, S. H., Young, S. C., Lin, J. L., and Lin, P. L. (2011). Involvement of PI3K/Akt signaling in PTTHstimulated ecdysteroidogenesis by prothoracic glands of the silkworm, Bombyx mori. Insect Biochem. Mol. Biol. 41, 197-202.

Halder, G., and Johnson, R. L. (2011). Hippo signaling: growth control and beyond. Development 138, 9-22.

Halme, A., Cheng, M., and Hariharan, I. K. (2010). Retinoids regulate a developmental checkpoint for tissue regeneration in Drosophila. Curr. Biol. 20, 458-463.

Hampton, S. R. J., and Peet, D. J. (2009). From polyps to people: a highly familiar response to hypoxia. Ann. N. Y. Acad. Sci. 1177, 19-29.

Hillesheim, E., and Stearns, S. C. (1992). Correlated responses in life-history traits to artificial selection for body weight in Drosophila melanogaster. Evolution 46, 745-752.

$\mathrm{Hu}, \mathrm{X}$. , Cherbas, L., and Cherbas, P. (2003). Transcription activation by the ecdysone receptor (EcR/USP): identification of activation functions. Mol. Endocrinol. 17, 716-731.

Huey, R. B., Gilchrist, G. W., Carlson, M. L., Berrigan, D., and Serra, L. (2000). Rapid evolution of a geographic cline in size in an introduced fly. Science 287, 308-309.

Hull-Thompson, J., Muffat, J., Sanchez, D., Walker, D. W., Benzer, S., Ganfornina, M. D., and Jasper, H. (2009). Control of metabolic homeostasis by stress signalin is mediated by the lipocalin NLaz. PLoS Genet. 5, e1000460. doi:10.1371/journal.pgen. 1000460

Ikeya, T., Broughton, S., Alic, N., Grandison, R. C., and Partridge, L. (2009). The endosymbiont Wolbachia increases insulin/IGF-like signalling in Drosophila. Proc. Biol. Sci. 276, 3799-3807.

Ikeya, T., Galic, M., Belawat, P., Nairz, K., and Hafen, E. (2002). Nutrientdependent expression of insulin-like peptides from neuroendocrine cells in the CNS contributes to growth regulation in Drosophila. Curr. Biol. 12, 1293-1300.

James, A. C., Azevedo, R. B., and Partridge, L. (1995). Cellular basis and developmental timing in a size cline of Drosophila melanogaster. Genetics 140, 659-666.

James, A. C., Azevedo, R. B., and Partridge, L. (1997). Genetic and environmental responses to temperature of Drosophila melanogaster from a latitudinal cline. Genetics 146 881-890.
James, A. C., and Partridge, L. (1995). Thermal evolution of rate of larval development in Drosophila melanogaster in laboratory and field populations. J. Evol. Biol. 8, 315-330.

Kim, D. H., Sarbossov, D. D., Ali, S. M., King, J. E., Latek, R. R., ErdjumentBromage, H., Tempst, P., and Sabatini, D. M. (2002). MTOR interacts with RAPTOR to form a nutrientsensitive complex that signals to the cell growth machinery. Cell 110, 163-175.

Klok, C. J., and Harrison, J. F. (2009). Atmospheric hypoxia limits selection for large body size in insects. PLoS ONE 4, e3876. doi:10.1371/journal.pone.0003876

Koelle, M., Talbot, W. S., Segraves, W. A., Bender, M. T., Cherbas, P., and Hogness, D. S. (1991). The Drosophila EcR gene encodes an ecdysone receptor, a new member of the steroid receptor superfamily. Cell 67, 59-77.

Kramer, J., Davidge, J., Lockyer, J., and Staveley, B. (2003). Expression of Drosophila FOXO regulates growth and can phenocopy starvation. BMC Dev. Biol. 3, 5. doi:10.1186/1471-213X-3-5

Layalle, S., Arquier, N., and Léopold, P. (2008). The TOR pathway couples nutrition and developmental timing in Drosophila. Dev. Cell 15, 568-577.

Lecuit, T., and Le Goff, L. (2007). Orchestrating size and shape during morphogenesis. Nature 450, 189-192.

Loehlin, D. W., and Werren, J. H. (2012). Evolution of shape by multiple regulatory changes to a growth gene. Science 335, 943-947.

McBrayer, Z., Ono, H., Shimell, M., Parvy, J. P., Beckstead, R. B., Warren, J. T., Thummel, C. S., DauphinVillemant, C., Gilbert, L. I., and O'Connor, M. B. (2007). Prothoracicotropic hormone regulates developmental timing and body size in Drosophila. Dev. Cell 13, 857-871.

Mesquita, D., Dekanty, A., and Milán, M. (2010). A dp53-dependent mechanism involved in coordinating tissue growth in Drosophila. PLoS Biol. 8, e1000566. doi:10.1371/journal.pbio. 1000566

Mirth, C. K., Truman, J. W., and Riddiford, L. M. (2005). The role of the prothoracic gland in determining critical weight for metamorphosis in Drosophila melanogaster. Curr. Biol. 15, 1796-1807.

Mirth, C. K., Truman, J. W., and Riddiford, L. M. (2009). The Ecdysone receptor controls the post-critical weight switch to nutritionindependent differentiation in 
Drosophila wing imaginal discs. Development 136, 2345-2353.

Morata, G., Shlevkov, E., and PerezGarijo, A. (2011). Mitogenic signaling from apoptotic cells in Drosophila. Dev. Growth Differ. 53, 168-176.

Nijhout, H. F. (1975). A threshold size for metamorphosis in the tobacco hornworm, Manduca sexta (L.). Biol. Bull. 149, 214-225.

Nijhout, H. F., and Grunert, L. W. (2002). Bombyxin is a growth factor for wing imaginal discks in Lepidoptera. Proc. Natl. Acad. Sci. U.S.A. 99, 15446-15450.

Nijhout, H. F., and Grunert, L. W. (2010). The cellular and physiological mechanism of wing-body scaling in Manduca sexta. Science 330, 1693-1695.

Nijhout, H. F., Smith, W. A., Schachar, I., Subramanian, S., Tobler, A., and Grunert, L. W. (2007). The control of growth and differentiation of the wing imaginal disks of Manduca sexta. Dev. Biol. 302, 569-576.

Nijhout, H. F., and Williams, C. M. (1974a). Control of molting and metamorphosis in the tobacco hornworm, Manduca sexta (L.): growth of the last-instar larva and the decision to pupate. J. Exp. Biol. 61, 481-491.

Nijhout, H. F., and Williams, C. M. (1974b). Control of molting and metamorphosis in the tobacco hornworm, Manduca sexta (L.): cessation of juvenile hormone secretion as a trigger for pupation. J. Exp. Biol. 61, 493-501.

Nunney, L., and Cheung, W. (1997). The effect of temperature on body size and fecundity in female Drosophila melanogaster: evidence for adaptive plasticity. Evolution 51, 1529-1535.

Okamoto, N., Yamanaka, N., Yagi, Y., Nishida, Y., Kataoka, H., O'Connor, M. B., and Mizoguchi, A. (2009). A fat body-derived IGF-like peptide regulates postfeeding growth in Drosophila. Dev. Cell 17, 885-891.

$\mathrm{Ou}, \mathrm{Q}$., Magico, A., and King-Jones, K. (2011). Nuclear receptor DHR4 controls the timing of steroid hormone pulses during Drosophila development. PLoS Biol. 9, e1001160. doi:10.1371/journal.pbio. 1001160

Pan, D. (2007). Hippo signaling in organ size control. Genes Dev. 21, 886-897.

Parker, N. F., and Shingleton, A. W. (2011). The coordination of growth among Drosophila organs in response to localized growthperturbation. Dev. Biol. 357, 318-325.

Partridge, L., Barrie, B., Fowler, K., and French, V. (1994). Evolution and development of body size and cell size in Drosophila melanogaster in response to temperature. Evolution $48,1269-1276$.

Partridge, L., and Fowler, K. (1993). Responses and correlated responses to artificial selection on thorax length in Drosophila melanogaster. Evolution 47, 213-226.

Partridge, L., Langelan, R., Fowler, K., Zwaan, B., and French, V. (1999). Correlated responses to selection on body size in Drosophila melanogaster. Genet. Res. 74, 43-54.

Peck, L. S., and Maddrell, S. H. P. (2005). Limitation of size by hypoxia in the fruit fly Drosophila melanogaster. J. Exp. Zoolog. Part A Comp. Exp. Biol. 303A, 968-975.

Potter, C. J., Huang, H., and Xu, T. (2001). Drosophila Tsc1 functions with Tsc2 to antagonize insulin signaling in regulating cell growth, cell proliferation, and organ size. Cell 105, 357-368.

Powis, G., Bonjouklian, R., Berggren, M. M., Gallegos, A., Abraham, R., Ashendel, C., Zalkow, L., Matter, W. F., Dodge, J., Grindey, G., and Vlahos, C. J. (1994). Wortmannin, a potent and selective inhibitor of phosphatidylinositol-3-kinase. Cancer Res. 54, 2419-2423.

Ray, C. (1960). The application of Bergmann's and Allen's rules to the poikilotherms. J. Morphol. 106, 85-108.

Reeve, E. C. R. (1954). Natural selection for body size in Drosophila. Proceedings of the International Congress of Genetics 9, 854-855.

Rewitz, K. F., Yamanaka, N., Gilbert, L. I., and O'Connor, M. B. (2009). The insect neuropeptide PTTH activates receptor tyrosine kinase torso to initiate metamorphosis. Science 326, 1403-1405.

Riddiford, L. M. (1993). "Hormones and Drosophila development," in The Development of Drosophila melanogaster, Vol. 2, eds M. Bates and A. Martinez-Arias (Plainview, TX: Cold Spring Harbor Laboratory Press), 899-939.

Riddiford, L. M., Truman, J. W., Mirth, C. K., and Shen, Y. C. (2010). A role for juvenile hormone in the prepupal development of Drosophila melanogaster. Development 137, 1117-1126.

Roberts, B., Henrich, V., and Gilbert, L. I. (1987). Effects of photoperiod on the timing of larval wandering in Drosophila melanogaster. Physiol. Entomol. 12, 175-180.

Robertson, F. B. (1963). The ecological genetics of growth in Drosophila. 6. The genetic correlation between the duration of the larval period and body size in relation to larval diet. Genet. Res. 4, 74-92.

Robinson, S. J. W., and Partridge, L. (2001). Temperature and clinal variation in larval growth efficiency in Drosophila melanogaster. J. Evol. Biol. 14, 14-21.

Rogulja, D., Rauskolb, C., and Irvine, K. D. (2008). Morphogen control of wing growth through the Fat signaling pathway. Dev. Cell 15 309-321.

Rulifson, E. J., Kim, S. K., and Nusse, R. (2002). Ablation of insulinproducing neurons in flies: growth and diabetic phenotypes. Science 296, 1118-1120

Santos, M., Fowler, K., and Partridge, L. (1994). Gene-environment interaction for body size and larval density in Drosophila melanogaster: an investigation of effects on development time, thorax length and adult sex-ratio. Heredity 72 515-521.

Sarbassov, D. D., Guertin, D. A., Ali, S. M., and Sabatini, D. M. (2005). Phosphorylation and regulation of Akt/PKB by the Rictor-mTOR complex. Science 307, 1098-1101.

Saucedo, L. J., Gao, X., Chiarelli, D. A., Li, L., Pan, D., and Edgar, B. A. (2003). Rheb promotes cell growth as a component of the insulin/TOR signaling network. Nat. Cell Biol. 5, 566-571.

Schubiger, M., Carre, C., Antoniewski, C., and Truman, J. W. (2005). Ligand-dependent de-repression via $\mathrm{EcR} / \mathrm{USP}$ acts as a gate to coordinate the differentiation of sensory neurons in the Drosophila wing. Development 132, 5239-5248.

Schubiger, M., and Truman, J. W. (2000). The RXR ortholog USP suppresses early metamorphic processes in Drosophila in the absence of ecdysteroids. Development 127, 1151-1159.

Shingleton, A. W. (2010). The regulation of organ size in Drosophila: physiology, plasticity, patterning and physical force. Organogenesis 6, 76-87.

Shingleton, A. W., Das, J., Vinicius, L., and Stern, D. L. (2005). The temporal requirements for insulin signalling during development in Drosophila. PLoS Biol. 3, e289. doi:10.1371/journal.pbio.0030289

Shingleton, A. W., Estep, C. M., Driscoll, M. V., and Dworkin, I. (2009). Many ways to be small: different environmental regulators of size generate distinct scaling relationships in Drosophila melanogaster. Proc. Biol. Sci. 276, 2625-2633.
Simpson, P., Berreur, P., and BerreurBonnenfant, J. (1980). The initiation of pupariation in Drosophila: dependence on growth of the imaginal discs. J. Embryol. Exp. Morphol. 57, 155-165.

Slaidina, M., Delanoue, R., Gronke, S., Partridge, L., and Léopold, P. (2009). A Drosophila insulin-like peptide promotes growth during nonfeeding states. Dev. Cell 17, 874-884.

Sopko, R., Silva, E., Clayton, L., Gardano, L., Barrios-Rodiles, M., Wrana, J., Varelas, X., Arbouzova, N. I., Shaw, S., Saburi, S., Matakatsu, H., Blair, S., and McNeill, H. (2009). Phosphorylation of the tumor suppressor fat is regulated by its ligand Dachsous and the kinase discs overgrown. Curr. Biol. 19, 1112-1117.

Stieper, B. C., Kupershtok, M., Driscoll, M. V., and Shingleton, A. W. (2008). Imaginal discs regulate developmental timing in Drosophila melanogaster. Dev. Biol. 321, 18-26.

Storelli, G., Defaye, A., Erkosar, B., Hols, P., Royet, J., and Leulier, F. (2011) Lactobacillus plantarum promotes Drosophila systemic growth by modulating hormonal signals through TOR-dependent nutrient sensing. Cell Metab. 14, 403-414.

Sun, G., and Irvine, K. D. (2011). Regulation of Hippo signaling by Jun kinase signaling during compensatory cell proliferation and regeneration, and in neoplastic tumors. Dev. Biol. 350, 139-151.

Sutter, N. B., Bustamante, C. D., Chase, K., Gray, M. M., Zhao, K., Zhu, L., Padhukasahasram, B., Karlins, E., Davis, S., Jones, P. G., Quignon, P., Johnson, G. S., Parker, H. G., Fretwell, N., Mosher, D. S., Lawler, D. F., Satyaraj, E., Nordborg, M., Lark, K. G., Wayne, R. K., and Ostrander, E. A. (2007). A single IGF1 allele is a major determinant of small size in dogs. Science 316, 112-115.

Tang, H. Y., Smith-Caldas, M. S. B., Driscoll, M. V., Salhadar, S., and Shingleton, A. W. (2011). FOXO regulates organ-specific phenotypic plasticity in Drosophila. PLoS Genet. 7, e1002373. doi:10.1371/journal.pgen.1002373

Truman, J. W., and Riddiford, L. M. (1974). Physiology of insect rhythms. III. The temporal organization of the endocrine events underlying pupation of the tobacco hornworm. J. Exp. Biol. 60, 371-382.

Turner, T. L., Stewart, A. D., Fields, A. T., Rice, W. R., and Tarone, A. M. (2011). Population-based resequencing of experimentally evolved populations reveals the 
genetic basis of body size variation in Drosophila melanogaster. PLoS Genet. 7, el001336. doi:10.1371/journal.pgen.1001336 van't Land, J., Van Putten, W. F., Villarroel, H., Kamping, A., and van Delden, W. (2000). Latitudinal variation for two enzyme loci and an inversion polymorphism in Drosophila melanogaster from Central and South America. Evolution 54, 201-209.

Varelas, X., and Wrana, J. L. (2011). Coordinating developmental signaling: novel roles for the Hippo pathway. Trends Cell Biol. 22, 88-96.

Warren, J. T., Yerushalmi, Y., Shimell, M. J., O'Connor, M. B., Restifo, L. L., and Gilbert, L. I. (2006). Discrete pulses of molting hormone, 20-hydroxyecdysone, during late larval development of Drosophila melanogaster: correlations with changes in gene activity. Dev. Dyn. 235, 315-326.

Weeks, A. R., McKechnie, S. W., and Hoffmann, A. A. (2002). Dissecting adaptive clinal variation: markers, inversions and size/stress associations in Drosophila melanogaster from a central field population. Ecol. Lett. 5, 756-763.

Wullschleger, S., Loewith, R., and Hall, M. N. (2006). TOR signaling in growth and metabolism. Cell 124, 471-484.

Yao, T. P., Segraves, W. A., Oro, A. E., McKeown, M., and Evans, R. M. (1992). Drosophila ultraspiracle modulates ecdysone receptor function via heterodimer formation. Cell 71, 63-72.

Yenush, L., Fernandez, R., Myers, M. G. J., Grammer, T. C., Sun, X. J., Blenis, J., Pierce, J. H., Schlessinger, J., and White, M. F. (1996). The Drosophila insulin receptor activates multiple signaling pathways but requires insulin receptor substrate proteins for DNA synthesis. Mol. Cell. Biol. 16, 2509-2517.

Yu, J., Li, J., Zhang, S., Xu, X., Zheng, M., Jiang, G., and Li, F. (2012). IGF-1 induces hypoxia-inducible factor $1 \alpha$-mediated GLUT3 expression through PI3K/Akt/mTOR dependent pathways in PC12 cells. Brain Res. 1430, 18-24.

Zhang, L., Ren, F., Zhang, Q., Chen, Y., Wang, B., and Jiang, J. (2008). The TEAD/TEF family of transcription factor Scalloped mediates Hippo signaling in organ size control. Dev. Cell 14, 377-387.

Zhou, D., Udpa, N., Gersten, M., Visk, D. W., Bashir, A., Xue, J., Frazer, K. A., Posakony, J. W., Subramaniam, S., Barna, V., and Haddad, G. G. (2011). Experimental selection of hypoxia-tolerant Drosophila melanogaster. Proc. Natl. Acad. Sci. U.S.A. 108, 2349-2354.

Zhou, D., Xue, J., Chen, J., Morcillo, P., Lambert, J. D., White, K. P., and Haddad, G. G. (2007). Experimental selection for Drosophila survival in extremely low $\mathrm{O} 2$ environment. PLoS ONE 2, e490. doi:10.1371/journal.pone. 0000490
Conflict of Interest Statement: The authors declare that the research was conducted in the absence of any commercial or financial relationships that could be construed as a potential conflict of interest.

Received: 31 January 2012; paper pending published: 21 February 2012; accepted: 12 March 2012; published online: 03 April 2012.

Citation: Mirth CK and Shingleton AW (2012) Integrating body and organ size in Drosophila: recent advances and outstanding problems. Front. Endocrin. 3:49. doi: 10.3389/fendo.2012.00049

This article was submitted to Frontiers in Experimental Endocrinology, a specialty of Frontiers in Endocrinology.

Copyright (C) 2012 Mirth and Shingleton. This is an open-access article distributed under the terms of the Creative Commons Attribution Non Commercial License, which permits noncommercial use, distribution, and reproduction in other forums, provided the original authors and source are credited. 